ISSN 0103-8478

\title{
Época de emergência de azevém e nabo sobre a habilidade competitiva da cultura da cevada
}

\author{
Time of emergency of ryegrass and wild radish on the competitive ability of barley crop
}

\author{
Siumar Pedro Tironi ${ }^{\mathrm{I}}$ Leandro Galon ${ }^{\mathrm{II}}$ Alexandre Ferreira da Silva ${ }^{\mathrm{III}}$ \\ Cíntia Maria Teixeira Fialho ${ }^{\mathrm{IV}}$ Paulo Roberto Ribeiro Rochav Autieres Teixeira Faria ${ }^{\mathrm{VI}}$ \\ Ignacio Aspiazú ${ }^{\mathrm{VII}}$ Cesar Tiago Forte ${ }^{\mathrm{II}}$ Antonio Alberto da Silva ${ }^{\mathrm{VI}}$ André Luiz Radünz ${ }^{\mathrm{II}}$
}

RESUMO

Objetivou-se com o trabalho avaliar os efeitos de épocas de emergência das plantas daninhas, azevém e nabo, sobre a cultura da cevada. O experimento foi conduzido em delineamento de blocos casualizados, arranjado em esquema fatorial $2 \times 5$, com três repetições. No fator A, foram alocadas as plantas competidoras (azevém e nabo) e no $B$ as épocas de emergência (14 e 07 dias antes, no mesmo dia, 07 e 14 dias depois da emergência da cultura). No início da floração da cevada, foram mensuradas as variáveis: estatura das plantas, número de colmos ou caules, área foliar e matéria seca da parte aérea da cultura e das plantas daninhas. Todas as variáveis avaliadas da cevada apresentaram aumento de valor com o atraso da emergência das plantas daninhas. As espécies, cultivada ou daninhas, que emergiram antes, apresentaram maior habilidade competitiva, dominando o ambiente quando emergiram 14 dias antes uma da outra. Quanto mais tarde ocorrer a emergência das plantas daninhas com relação à cultura, menor é a interferência e, desse modo, maior é a habilidade da cevada em competir com a espécie daninha pelos recursos disponíveis no meio.

Palavras-chave: Hordeum vulgare, Lolium multiflorum, Raphanus raphanistrum.

\section{ABSTRACT}

The objective was to evaluate the effects of times of emergence of the weed ryegrass species and wild radish on barley. The experiment was conducted in a randomized block design, arranged in a $2 \times 5$ factorial design, with three replicates. In factor A were allocated the competing species (ryegrass and wild radish) and in factor $B$ the emergence periods (14 and 7 days before, on the same day, 7 and 14 days after crop emergence). At the beginning of barley flowering, the following variables were quantified: plant height, number of stalks or stems, leaf area, and shoot dry mass of crop and weeds. All barley variables had increased in value with the delay in weed emergence. The species, cultivated or weeds, that emerged earlier showed greater competitive ability, dominating the environment when emerging 14 days before each other. The later the emergence of weeds with respect to the crop, the less the interference they cause, and, thereby, the crop presents a greater ability to compete with the weeds for available resources in the environment.

Key words: Hordeum vulgare, Lolium multiflorum, Raphanus raphanistrum.

\section{INTRODUÇÃO}

O manejo de plantas daninhas na cultura da cevada tem apresentado dificuldades em função do lento desenvolvimento inicial da cultura, do elevado número de sementes de plantas daninhas no solo e do reduzido número de herbicidas registrados. Nesse contexto, as plantas daninhas são consideradas os principais entraves para alavancar a área cultivada com cevada no País, em especial no Sul do Brasil. A ausência de controle da comunidade infestante, durante todo o ciclo da cultura, pode ocasionar perdas no rendimento de até 71\% (SCURSONI \& SATORRI,

ICurso de Agronomia, Universidade Federal da Fronteira Sul (UFFS), Câmpus Chapecó, Chapecó, SC, Brasil.

${ }^{\text {IIC }}$ urso de Agronomia, Manejo Sustentável dos Sistemas Agrícolas, UFFS, Campus Erechim, 99700-000, Erechim, RS, Brasil. E-mail: leandro.galon@uffs.edu.br. *Autor para correspondência.

IIIEmbrapa Milho e Sorgo, Sete Lagoas, MG, Brasil.

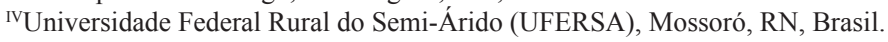

${ }^{v}$ Universidade Federal de Roraima (UFRR), Boa Vista, RR, Brasil.

VIUniversidade Federal de Viçosa (UFV), Viçosa, MG, Brasil.

VIIUniversidade Estadual de Montes Claros, Janaúba, MG, Brasil. 
2005), muitas vezes, limitando o destino do produto colhido, devido à qualidade deste.

Segundo GALON et al., (2011) estudos que abordem o efeito da interferência de plantas daninhas no desenvolvimento da cevada são de suma importância, por contribuir no processo de elaboração de estratégias para o manejo da comunidade infestante, devido ao baixo número de herbicidas registrados para tal fim. Ressalta-se que, na atualidade, tem-se utilizado o controle químico para o manejo de plantas daninhas em função da praticidade, eficiência e menor custo, quando comparados a outros métodos de controle.

O conhecimento dos períodos de interferência ou a habilidade competitiva das plantas daninhas infestantes das culturas é imprescindível para a implantação de programas de manejo integrado delas e assim permitir o uso mais racional dos métodos de controle, em especial o químico. Este que tem provocado sérios problemas de contaminação do homem, do ambiente ou mesmo o surgimento de plantas daninhas resistentes a herbicidas.

Convém destacar ainda que se torna necessário conhecer a época de emergência das plantas daninhas e o impacto destas sobre as culturas (CIUBERKIS et al., 2007). Propiciando, assim, a adoção de melhores estratégias de controle e nos momentos mais adequados durante o crescimento e desenvolvimento da cevada.

De maneira geral, as plantas daninhas que emergem depois da cultura exercem menor impacto na produtividade (VANDEVENDER et al., 1997). No entanto, as espécies que emergem antes podem dominar o ambiente, levando vantagem sobre as espécies que emergem tardiamente na competição pelos recursos do meio.

Dentre as principais plantas daninhas que infestam as lavouras de cereais de inverno do Sul do País, destacam-se o azevém (Lolium multiflorum) e o nabo (Raphanus raphanistrum). Essas espécies apresentam elevado potencial competitivo com a cevada, necessitando algum método de manejo para evitar perdas quantitativas e qualitativas, principalmente dos grãos da cevada destinados à indústria cervejeira.

Cabe ainda destacar que os programas de melhoramento genético têm procurado desenvolver cultivares que, com pequeno porte e pouco crescimento vegetativo, apresentem elevado acúmulo de fotoassimilados nas sementes. Com frequência, acréscimos na produtividade econômica de espécies cultivadas são acompanhados por decréscimo no potencial competitivo (PITELLI,
1985). Em decorrência disso, as plantas daninhas frequentemente levam vantagem competitiva sobre as cultivadas em condições semelhantes (GALON \& AGOSTINETTO, 2009). No entanto, para que ocorra competição, há necessidade de sobreposição suficiente dos nichos dos indivíduos que competem entre si, de modo que eles passem a utilizar os mesmos recursos do ambiente (COUSENS, 1991).

A melhor compreensão dos danos ocasionados pelas plantas daninhas ao emergirem em diferentes épocas, em relação à cultura, pode apresentar grande importância para a elaboração de estratégias ao se adotar o manejo integrado de plantas daninhas. Sendo assim, o objetivo deste trabalho foi verificar os efeitos da época de emergência das plantas daninhas, azevém e nabo, sobre a cultura da cevada.

\section{MATERIAL E MÉTODOS}

O experimento foi conduzido em ambiente protegido, sendo as unidades experimentais, constituídas por caixas de polietileno contendo $150 \mathrm{dm}^{3}$ de substrato e área superficial de $0,47 \mathrm{~m}^{2}$. Os tratamentos foram mantidos sob irrigação por microaspersão, deixando-se o solo com umidade próxima da capacidade de campo. Como substrato, foi utilizado um Latossolo Vermelho Amarelo, previamente corrigido e adubado de acordo com a recomendação técnica para cultura da cevada. O delineamento experimental utilizado foi de blocos casualizados, arranjado em esquema fatorial $2 \times 5$, com três repetições. No fator A, alocaram-se as plantas daninhas (azevém - Lolium multiflorum e nabo - Raphanus raphanistrum) e, no B, as épocas de emergência dessas espécies em relação à cultura, que foram de 14 e 07 dias antes, no mesmo dia, 07 e 14 dias após a emergência da cevada $(-14,-7,0$, 7, 14 dias em relação à emergência da cultura). Cabe destacar que as espécies de plantas daninhas remanescentes, não objeto deste estudo, foram controladas através da monda.

A cultivar de cevada utilizada foi a 'BRS Greta', sendo que, em cada caixa de polietileno, deixaram-se, após desbaste, 122 plantas de cevada, 94 de azevém e 24 de nabo. Desse modo, foi obtido um estande de 260, 50 e 200 plantas $\mathrm{m}^{-2}$ de cevada, nabo e azevém, respectivamente. As densidades populacionais de plantas daninhas, utilizadas no presente experimento são relatadas como as comumente encontradas em lavouras cultivadas com cereais de inverno (AGOSTINETTO et al., 2008).

Para que as espécies emergissem nas épocas determinadas pelos tratamentos, foi verificado, 
anteriormente, o período entre a semeadura e emergência destas. As espécies foram semeadas em bandejas com areia para realizar o transplante quando as plantas emergidas nas caixas de polietileno não atingissem as populações desejadas.

As avaliações das plantas cultivadas e das espécies daninhas foram realizadas no início do período de florescimento da cevada (50 dias após a emergência), sendo estas: estatura das plantas, número de colmos ou caules, área foliar e massa seca da parte aérea. Para medição da estatura das plantas, foram aferidas aleatoriamente dez plantas por caixas de polietileno, com régua graduada $(\mathrm{cm})$ desde rente ao solo até o ápice da folha bandeira. Posteriormente, todas as plantas foram seccionadas rente ao solo, sendo contabilizado o número de colmos ou caule das diferentes espécies. Em seguida, as plantas foram acondicionadas em sacos plásticos, separadamente, e levadas ao laboratório para estimativa da área foliar em determinador eletrônico de área foliar, marca Licor-3100. Após essa análise, o material vegetal foi acondicionado em sacos de papel, que foram alocados em estufa de circulação forçada de ar à temperatura de $65^{\circ} \mathrm{C}$ para desidratação até atingir massa constante, sendo após determinada a massa seca da parte aérea.

Os dados foram submetidos à análise de variância e quando o teste $F$ indicou significância, as médias dos tratamentos foram analisadas por regressões lineares e não lineares. A escolha dos modelos baseou-se na significância estatística (teste F), no ajuste do coeficiente de determinação $\left(R^{2}\right)$ e no significado biológico do modelo. Todos os testes foram realizados a $\mathrm{P} \leq 0,05$.

\section{RESULTADOS E DISCUSSÃO}

Todas as variáveis analisadas, tanto da cevada quanto do azevém ou do nabo, foram influenciadas pelas diferentes épocas de emergência das plantas daninhas em relação à cultura. Tal resultado é esperado tendo em vista que a competição entre plantas é parte fundamental na ecologia dos vegetais, quando duas ou mais plantas utilizam ou retiram recursos para seu crescimento e desenvolvimento, os quais estão limitados no ecossistema comum (AGOSTINETTO et al., 2008; GALON \& AGOSTINETTO, 2009).

O azevém é uma espécie que apresenta elevada habilidade competitiva (GALON et al., 2011), disputando com a cultura os recursos disponíveis no meio, como água, luz, $\mathrm{CO}_{2}$ e nutrientes. Desse modo, essa espécie provoca alterações na expressão do potencial produtivo da cevada e dificulta a expansão da área cultivada, além de causar interferência no crescimento e desenvolvimento e reduzir a produtividade e a qualidade dos grãos (NUNES et al., 2007). Conforme observado nos resultados, o efeito do azevém, quando emergiu antes da cevada, foi provocar uma redução de aproximadamente $81 \%$ no número de colmos da cultura (Figura 1A). O número de colmos da cevada diminuiu de 96,87 para 18,47 quando o azevém germinou 14 dias depois e 14 dias antes da cultura, respectivamente (Figura 1A). Esse resultado também pode ser associado à maior velocidade de desenvolvimento inicial e aumento da capacidade de emissão de perfilhos do azevém em relação à cevada, o que ocasionou, dessa forma, maior interferência negativa no desenvolvimento da cultura. Ressalta-se que o aumento do número de perfilhos é uma característica que permite às plantas ocuparem rapidamente o espaço e consequentemente suprimir o crescimento das plantas vizinhas, no caso a cevada.

A maior emissão de perfilhos do azévem pode ter provocado redução na quantidade e qualidade da luz incidente sobre a cevada, o que provocou redução no número de perfilhos deste último. A luz desempenha papel crítico na determinação da emissão, desenvolvimento e sobrevivência de perfilhos, principalmente em espécies gramíneas como a cevada e o azevém (ALMEIDA \& MUNDSTOCK, 2001).

À medida que a emergência do azevém foi se aproximando da data de emergência da cevada, observou-se o aumento no número de colmos da cultura em detrimento do número de colmos da planta daninha. Porém, mesmo quando a emergência das duas espécies foi simultânea, o número de perfilhos do azevém sobressaiu-se em relação à cevada, respectivamente 141,27 e 57,67, demonstrando, dessa forma, a agressividade desta espécie em ocupar o ambiente. A cevada somente apresentou maior número de colmos do que o azevém quando a emergência da espécie daninha foi, pelo menos, oito dias depois da cultura.

$\mathrm{O}$ acúmulo de massa seca da parte aérea da cevada foi afetado negativamente pelo azevém, quando este emergiu mais de quatro dias antes da cultura (Figura 1B). À medida que a data de emergência da planta daninha se aproxima da emergência da cultura, há o maior acúmulo de massa seca da cultura em detrimento da espécie infestante, respectivamente 41,20 e 26,04, para o azevém e para a cevada na mesma data de germinação. Essa variável pode servir como um indicador de habilidade competitiva; o seu maior acúmulo pode indicar que a planta se sobressaiu na utilização dos recursos do meio. GALON et al. (2011), ao avaliarem a 


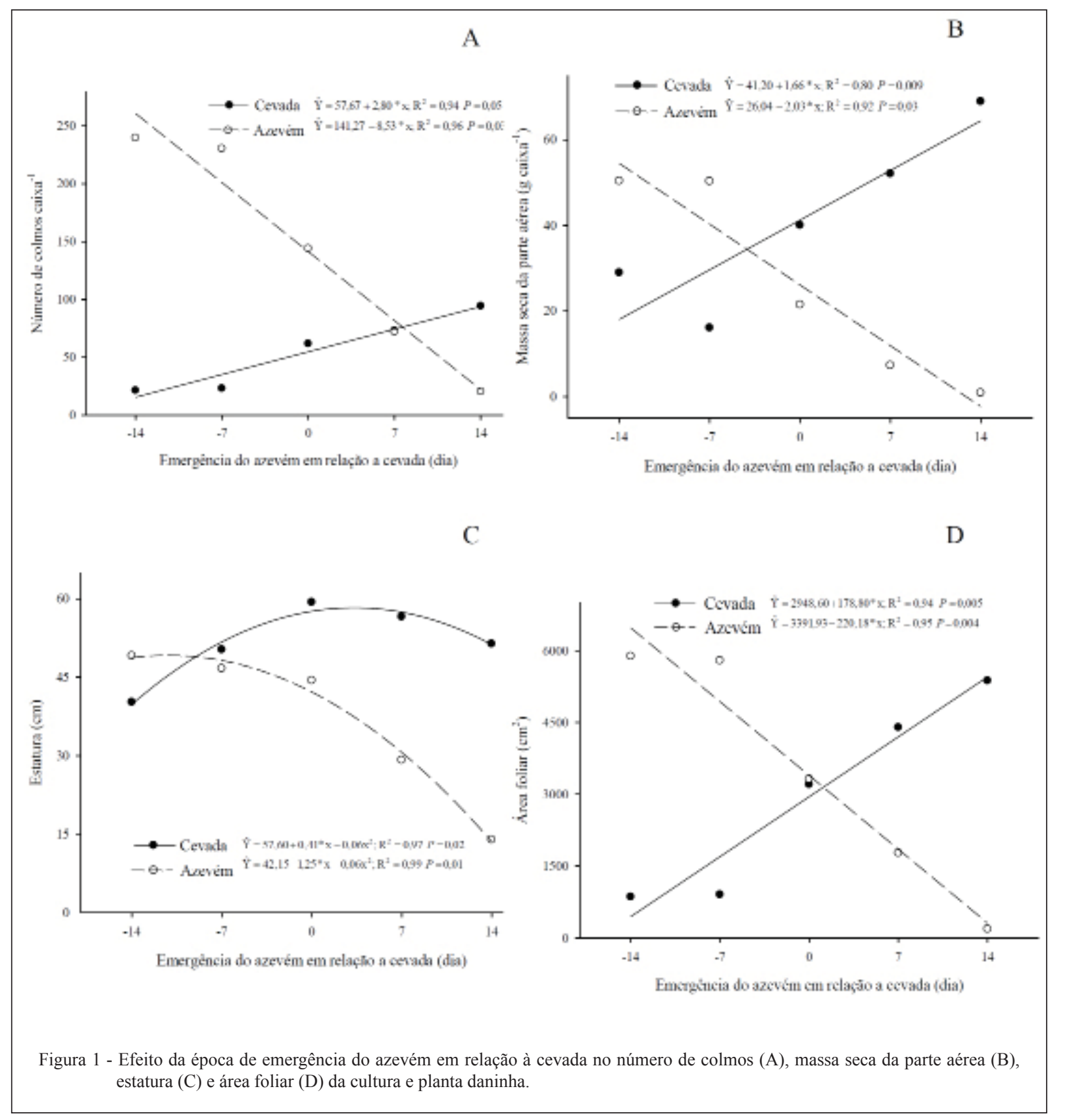

habilidade competitiva de diferentes cultivares de cevada na presença de azevém, observaram que essa espécie daninha pode reduzir drasticamente o acúmulo de massa seca da cultura, principalmente em altas densidades.

A cultura somente apresentou menor estatura que o azevém quando esta emergiu após 10 dias que a planta daninha (Figura 1C). Esse resultado demonstra que, ao invés de alocar recursos na emissão de perfilhos (Figura 1A), as plantas de cevada investiram no desenvolvimento de sua estatura. Resultado semelhante foi observado por AGOSTINETTO et al. (2008) ao avaliarem o efeito da interferência da comunidade infestante sobre a cultura do trigo. Os autores observaram que as plantas de trigo, quando em convivência com a comunidade infestante, de 0 a 42 dias após a emergência, apresentavam maior estatura e menor número de perfilhos que aquelas que cresceram livre da interferência de plantas daninhas durante todo o ciclo. O maior investimento de fotoassimilados no desenvolvimento vertical é uma estratégia 
adotada por algumas plantas que competem por luz para obter vantagem na captação desse recurso do ambiente (RAJCAN \& SWANTON, 2001). Esse comportamento é típico das plantas que são submetidas à competição, no entanto, o maior investimento em estatura e menor formação de perfilhos torna a cultura menos produtiva (AGOSTINETTO et al., 2008) ou os colmos menos resistentes ao acamamento, o que também não é desejável.

A área foliar da cevada foi menor à medida que as datas de emergência do azevém foram se antecipando em relação à cultura. Quando a planta daninha e a cultura emergiram simultaneamente (no mesmo dia) as áreas foliares se equivaleram (Figura 1D). O rápido incremento da área foliar é uma estratégia utilizada por plantas altamente competitivas, que resultam em maior sombreamento de seus vizinhos, ocasionando, dessa forma, redução na capacidade competitiva da espécie sombreada, principalmente se estas apresentarem metabolismo fotossintético $\mathrm{C}_{4}$ (ALMEIDA \& MUNDSTOCK, 2001)

O número de colmos da cevada apresentou aumento linear à medida que o tempo de emergência da cultura avançava em relação à do nabo (Figura 2A). Observou-se redução de, aproximadamente, $50 \%$ no número de ramificações laterais do nabo quando se compara a sua emergência 14 dias antes e após a emergência da cultura. $\mathrm{O}$ nabo pertence à família das Brassicaceae e, ao contrário da cevada e do azevém, não apresenta a capacidade de emissão de perfilhos e sim emite ramificações. Dessa forma, para utilizar o espaço e dominar o ambiente, o nabo tem a capacidade de emitir ramificações laterais, formando plantas grandes, com maior área foliar, maior dossel, acúmulo de massa e capacidade de produção de sementes, mesmo quando em competição com a cevada (SOUZA \& VELINI, 1997). Os mesmos autores ressaltam ainda que o nabo, em curto espaço de tempo, quando não controlado, afeta significativamente o crescimento e o desenvolvimento da cevada.

O acúmulo de massa seca da parte aérea da cevada apresentou aumento linear à medida que a época de emergência da cultura se aproximou e antecedeu a do nabo. Por outro lado, a massa seca da planta daninha diminuiu de forma exponencial com o atraso da germinação, em relação à cultura (Figura 2B). Quando as duas plantas emergiram simultaneamente, a cevada apresentou maior acúmulo de massa seca do que o nabo, evidenciando assim o maior potencial competitivo da cultura. A competição afeta quantitativa e qualitativamente a produção, pois modifica a eficiência de aproveitamento dos recursos disponíveis no meio (BIANCHI et al., 2006).

Em condição de competição, o nabo tende a alocar maior quantidade de recursos fotossintéticos no desenvolvimento de sua estatura (Figura 2C). A cultura somente apresentou maior estatura do que a planta daninha quando emergiu com mais de cinco dias de antecedência. Essas informações demonstram as diferentes estratégias adotadas pelas plantas quando em condição de estresse pela competição dos recursos do meio. A maior estatura das plantas daninhas em relação à cultura, além de causar perdas na produtividade, decorrentes do maior sombreamento, pode ocasionar, também, problemas durante a operação da colheita, com embuchamento de máquinas, menor velocidade de colheita, aumento do teor de umidade e de impurezas dos grãos ou sementes da cevada, contribuindo assim para perdas da qualidade e quantidade de grãos ou sementes produzidos. Salienta-se que, para a cevada ser utilizada como matéria-prima para a fabricação de cervejas, ela necessita apresentar uma porcentagem de germinação maior do que $95 \%$ e estar livre de impurezas. Desse modo, torna-se de extrema importância o manejo de plantas daninhas infestantes dessa cultura, em especial o azevém e o nabo.

A cultura, mesmo emergindo sete dias após o nabo, apresentou maior área foliar do que a espécie daninha (Figura 2D). A maior área foliar da cevada pode ser atribuída ao maior número de colmos apresentados pela cultura em função do maior perfilhamento. $\mathrm{O}$ incremento desta variável pode ser compreendido como uma das maneiras da planta aumentar a superfície fotossintética, assegurando aproveitamento mais eficiente das baixas intensidades luminosas, decorrentes do maior sombreamento ocasionado pelo nabo.

Os resultados indicam que o período de estabelecimento da cevada pode ser uma importante estratégia utilizada no manejo de plantas daninhas, pois as plantas que emergiram após a cultura apresentaram menor crescimento e desenvolvimento, tornando-se menos competitivas e causando menor interferência sobre a cultura. A espécie que emergir antes, seja a cultura ou planta daninha, tem maior capacidade de extrair os recursos do meio, dominando assim o ambiente, desenvolvendo-se mais que a espécie que emerge posteriormente.

\section{CONCLUSÃO}

Constatou-se, para todas as variáveis analisadas, que tanto a cevada quanto o azevém e o nabo, foram influenciadas pelas diferentes épocas 

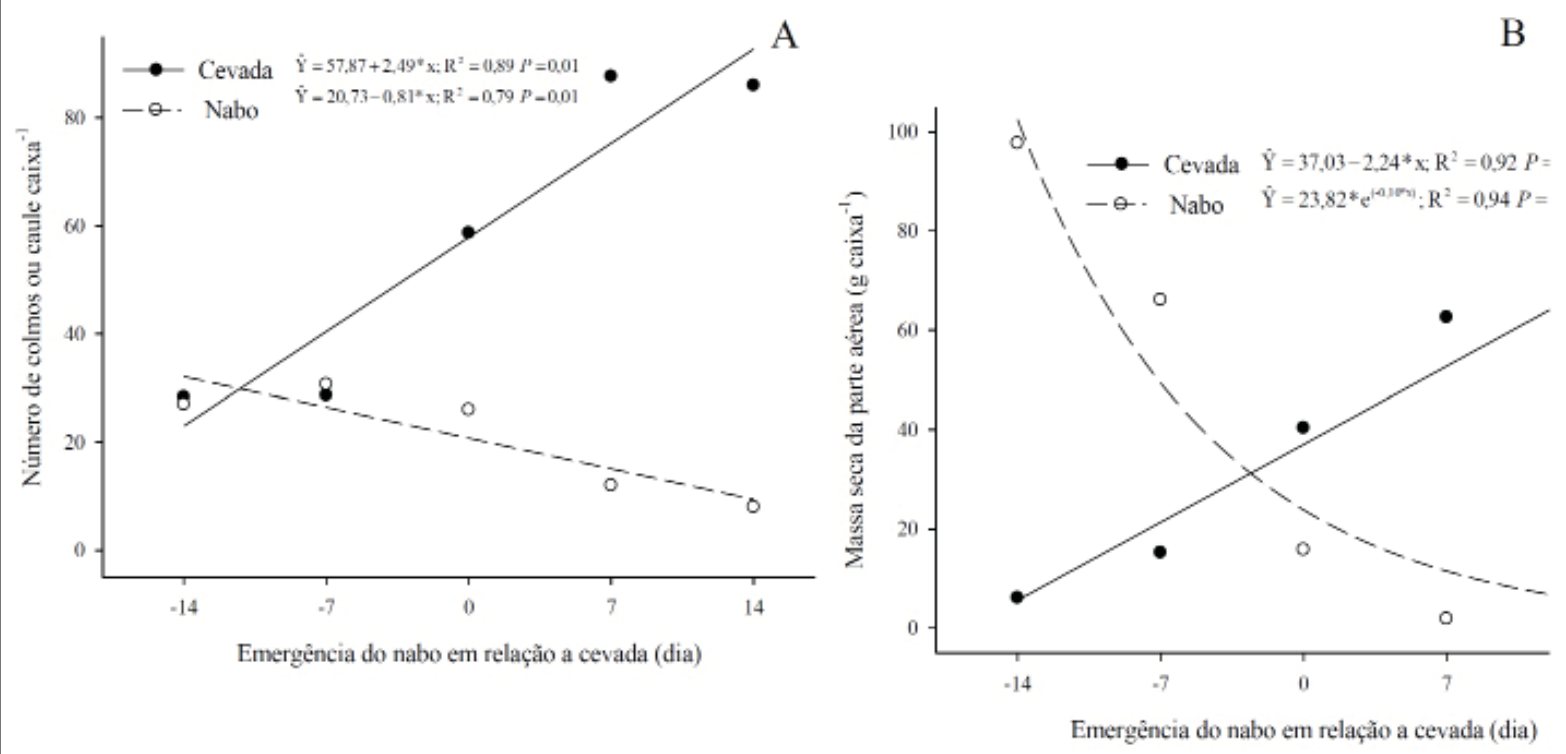

$\mathrm{C}$
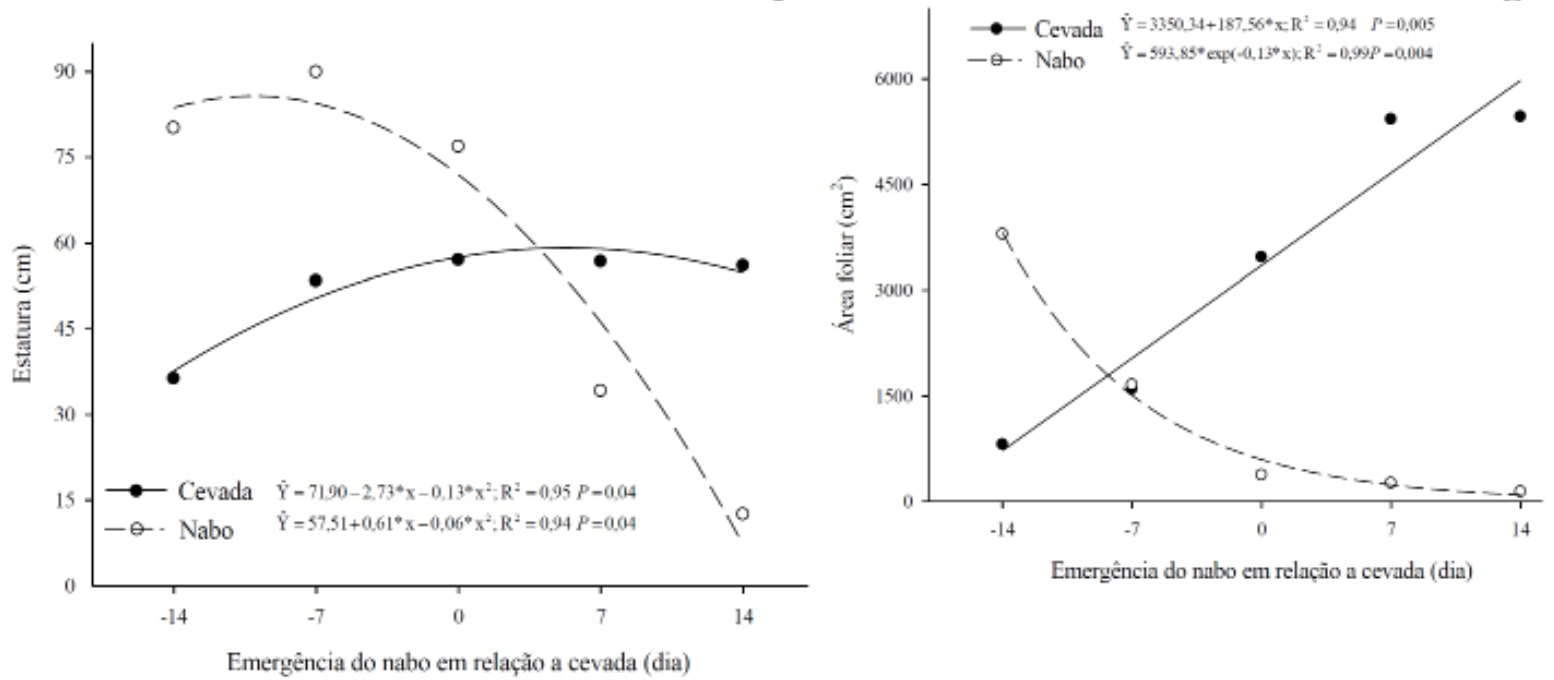

Figura 2 - Efeito da época de emergência do nabo em relação ao número de colmos da cevada e de caule do nabo (A), massa seca da parte aérea (B), estatura (C) e área foliar (D) da cultura e da planta daninha.

de emergência das plantas daninhas em relação à cultura. A emergência antecipada do azevém e do nabo em relação à cevada proporciona maior habilidade competitiva das plantas daninhas em detrimento da cultura. A cevada apresentou maior habilidade competitiva que o azevém e o nabo quando esta emergiu 08 dias antes que as planta daninhas. Entre as plantas daninhas testadas, o azevém demonstrou maior habilidade competitiva que o nabo, para as variáveis avaliadas, ao competirem com a cevada.

\section{AGRADECIMENTO}

Os autores agradecem ao Conselho Nacional de Desenvolvimento Científico e Tecnológico (CNPq) e a Fundação de Amparo a Pesquisa do Estado do Rio Grande do Sul (FAPERGS), pela concessão de auxílio financeiro à pesquisa de Leandro Galon (processos números 482144/2012-2/CNPq e 12/2265-3/FAPERGS). 


\section{REFERÊNCIAS}

AGOSTINETTO, D. et al. Período crítico de competição de plantas daninhas com a cultura do trigo. Planta Daninha, v.26, p.271-278, 2008. Disponível em: <http://www.scielo. br/scielo.php?pid $=\mathrm{S} 0100-83582008000200003 \&$ script $=$ sci arttext>. Acesso em: 12 ago. 2013. doi: 10.1590/S010083582008000200003 .

ALMEIDA, L.A.; MUNDSTOCK, C.M. A qualidade da luz afeta o afilhamento em plantas de trigo, quando cultivadas sob competição. Ciência Rural, v.31,p.401-408,2001. Disponívelem: $<$ http://www.scielo. br/scielo.php?pid=S0103-84782001000300006\&script=sci_arttext $>$. Acesso em: 21 nov. 2013. doi: 10.1590/S0103-84782001000300006.

BIANCHI, M.A. et al. Proporção entre plantas de soja e plantas competidoras e as relações de interferência mútua. Ciência Rural, v.36, p.1380-1387, 2006. Disponível em: <http://www.scielo.br/ scielo.php?pid=S0103-84782006000500006\&script=sci_arttext $>$. Acesso em: 12 out. 2013. doi: 10.1590/S0103-84782006000500006.

CIUBERKIS, S. et al. Effect of weed emergence time and intervals of weed and crop competition on potato yield. Weed Technology, v.21, p.213-218, 2007. Disponível em: <http://www.bioone.org/ doi/abs/10.1614/WT-06-101.1>. Acesso em: 22 set. 2013. doi: 10.1614/WT-06-101.1.

COUSENS, R. Aspects of the design and interpretation of competition (interference) experiments. Weed Technology, v.5, p.664-673, 1991. Disponível em: <http://www.jstor.org/disco ver $/ 10.2307 / 3987056$ ?uid $=375110901 \&$ uid $=3737664 \&$ uid $=59$ $09624 \&$ uid $=2 \&$ uid $=3 \&$ uid $=2459159455 \&$ uid $=67 \&$ uid $=62 \& \mathrm{~s}$ id $=21103106221333>$. Acesso em: 13 set. 2013.

GALON, L.; AGOSTINETTO, D. Comparison of empirical models for predicting yield loss of irrigated rice (Oryza sativa) mixed with Echinochloa spp. Crop Protection, v.28, p.825-830, 2009. Disponível em: <http://www.sciencedirect.com/science/ article/pii/S026121940900146X>. Acesso em 12 out. 2013.
GALON, L. et al. Habilidade competitiva de cultivares de cevada convivendo com azevém. Planta Daninha, v.29, p.771-781, 2011. Disponível em: <http://www.scielo.br/scielo.php?pid=S010083582011000400007\&script $=$ sci arttext $>$. Acesso em: 17 out. 2013. doi: $10.1590 / \mathrm{S} 0100-83582011000400007$.

NUNES, A.L. et al. Tolerância de espécies de inverno a herbicidas residuais. Scientia Agrária, v.8, p.443-448, 2007. Disponível em: <http://ojs.c3sl.ufpr.br/ojs/index.php/agraria/article/view/9895>. Acesso em: 24 ago. 2013

PITELLI, R.A. Interferência de plantas daninhas em culturas agrícolas. Informe Agropecuário, v.11, n.129, p.16-17, 1985.

RAJCAN, I.; SWANTON, C.J. Understanding maize-weed competition: resource competition, light quality and the whole plant. Field Crops Research, v.71, p 139-150, 2001. Disponível em: <http://www.sciencedirect.com/science/article/pii/ S0378429001001599>. Acesso em: 24 set. 2013.

SCURSONI, J.A.; SATORRE, E.H. Barley (Hordeum vulgare) and wild oat (Avena fatua) competition is affected by crop and weed density. Weed Technology, v.19, p.790-795, 2005. Disponível em: <http://www.bioone.org/doi/pdf/10.1614/WT03-065R.1>. Acesso em: 28 set. 2013. doi: 10.1614/WT-03065R.1

SOUZA, J.R.P.; VELINI, E.D. Efeitos da cultura da cevada e de períodos de controle sobre o crescimento e produção de sementes de Raphanus sativus L. Planta Daninha, v.15, p.97-103, 1997. Disponível em: <http://www.scielo.br/pdf/pd/v15n2/a02v15n2. pdf $>$. Acesso em: 12 nov. 2013.

VANDEVENDER, K.W. et al. Model of rice (Oryza sativa) yield reduction as a function of weed interference. Weed Science, v.45, p.218-224, 1997. Disponível em: <http://www.jstor.org/di scover $/ 10.2307 / 4046079$ ?uid $=375110901 \&$ uid $=3737664 \&$ uid $=$ $5909624 \&$ uid $=2 \&$ uid $=3 \&$ uid $=2459159455 \&$ uid $=67 \&$ uid $=62 \& \mathrm{~s}$ id=21103106221333 >. Acesso em: 11 out. 2013. 